American Journal of Biochemistry and Biotechnology 5 (1): 7-13, 2009

ISSN 1553-3468

(C) 2009 Science Publications

\title{
Lectin Histochemistry Assay in Colon Tissues for Inter-species Characterization
}

\author{
${ }^{1}$ Faezeh Yazdani Moghaddam, ${ }^{2}$ Jamshid Darvish, ${ }^{1}$ Nasser Mahdavi Shahri, \\ ${ }^{3}$ A.S. Abdulamir and ${ }^{4}$ Siti Khalija Daud \\ ${ }^{1}$ Department of Biology, School of Science, Ferdowsi University of Mashhad \\ ${ }^{2}$ Rodents Group, Ferdowsi University, Mashhad, Iran, Institute of Bioscience \\ ${ }^{3}$ Microbiology Research, Institute of Bioscience, University Putra Malaysia, Malaysia \\ ${ }^{4}$ Department of Biology, Faculty of Science, University Putra Malaysia, Malaysia
}

\begin{abstract}
Problem statement: The digestive tract of animals including rodents has taxonomic and ecologic importance due to its ability in adaptation for different environments. Whereas colon absorbs water and carbohydrates, it has a vital role ecologically and physiologically and enjoys different histological structures in different rodents with various diets. Approach: Different rodent specimens belong to the family Muridae, namely Gerbilinae subfamily (Jerbillus nanus, Meriones Persicus, Meriones lybicus) Microtinae (Microtus, transcaspicus, Ellobius fascocapillus, Microtus sp.) Dipodidae (Alactage elater, Jucullus blanfordi) and scuridae (Funambulus penantii, spermophillus folvus), were studied via histochemistry techniques. Various parts of the digestive tract were removed and measured. Proximal colon was cut into $2-3 \mathrm{~cm}$ segments and fixed by bouin solution. The segments stained by lectin (PNA, WGA) chemochemistry. Results: Microscopic observations indicated that there were remarkable distinctions in the carbohydrates and glycoproteins content of the different layers of colon among different species of rodents. Both PNA and WGA lectin histochemistry showed high and significant discriminatory power among the studied species of rodents especially lectin staining in mucosal and absorptive cells $(\mathrm{p}<0.05)$. Goblet and epithelial cells showed much lower affinity to lectins. Conclusion: It was concluded that use of lectin histochemistry was a valid method for phylogenic characterization of rodents, may be other animals, depending on colon tissues. Moreover, Colon tissues proved to be highly distinct and variable among species of animals. This assay can also be used in determining the diet nature, geographical variation, diseases affection on different species of animals.
\end{abstract}

Key words: Rodents, glycoconjugate, histochemistry, lectins, colon

\section{INTRODUCTION}

Lectins are ubiquitous proteins of non-immune origin which are present in plants, microorganisms, animals and humans. Lectins bind specifically monosaccharides or oligosaccharide structures ${ }^{[1]}$. Lectins are protein compounds that have the ability for cellular agglutination and glyco-conjugates settling in cellular surface. These compounds are distributed widely in nature and can be found in plants, animals, fungi, bacteria and insects ${ }^{[2]}$. Lectins are naturally poly peptides that bind specifically to carbohydrate residues in term of glycoconjugates and have extensively been used as probes in studying the cell surface interaction in different species. The recognition of the ending sugar moieties and their role in evolution rhythm is performed through recognizing these sugars by materials called lectins ${ }^{[3]}$. Any protein linked to carbohydrates, not related to immune system and agglutinates polysaccharides and glyco-conjugates can be considered as lectin which is divided into 5 groups based on their tendency to sugars binding ${ }^{[4]}$. The binding of one molecule of lectin to a molecule of carbohydrate is non-covalent which is similar to antigen-antibody binding. In paraffin sections, lectins are traditionally studied via direct and indirect histochemical staining. In direct method, lectins are conjugated by flouroucins or enzymes and detected by fluorescence or light microscopy by adding Soubestra enzyme $^{[5]}$. In indirect method, lectins linked to a specific part in a tissue and are followed by antibody (anti lectin) or avidain-biotin addition.

Nowadays, Wheat Germ Agglutinin (WGA), Peanut Agglutinin (PNA) and Concavilin (Cona) are being used widely for studying sugar compounds on the surface of cells ${ }^{[6]}$. Great progress has been made in the 
Am. J. Biochem. \& Biotech., 5 (1): 7-13, 2009

recent years by some studies ${ }^{[6,7]}$ in understanding the crucial role played by lectins in many biological processes. The choice of proper lectin for such studies and its quality as a tool depends on lectin specificity. Many lectins are apparently specific for a certain monosaccharide, but they react with various oligosaccharide chains terminating with this sugar at different affinities. Therefore, quantitative differences in the reactivity pattern exist between various lectins recognizing the same terminal monosaccharide residue $^{[8]}$.

Lectin-binding studies are valuable for diseases diagnosis and comparative purposes where they can detect minute variations of lectins profile between normal and pathologic conditions of given tissues, different regions in the same organ, or homologous regions in specimens of different age, sex or species. Lectins have been widely used for preparative and analytical purposes in biochemistry, cell biology, immunology and related areas ${ }^{[9]}$.

Histochemical studies have demonstrated that mucous substances produced along the entire digestive tract in vertebrates are very similar in macromolecular properties and polymer structures. Nevertheless they can differ in their relationship with the specific functions carried out in the gastrointestinal tract ${ }^{[10]}$. Thus, the knowledge of lectins variations in mucin composition along the gastrointestinal tract is of help in elucidating functional, pathologic and even taxonomic problems.

Few studies have investigated the glycoconjugates in the gastroenteric mucosa by lectin histochemical methods ${ }^{[11]}$. Additional data would be very useful in characterizing the morpho-functional criteria of the digestive tract system and their variations among taxa, as well as their evolutionary and physiological implications.

The aim of the current study was to investigate the characteristic distribution of certain glycoconjucates that exist in the colon of various species of rodents by means of lectin histochemistry. Non-traditional histochemical investigation was used to characterize the glycoconjugates in the mucosa of proximal colon in different species of rodents in order to evaluate the variation in distribution of mucins and to provide clues to their functional and evolutionary significance.

\section{MATERIALS AND METHODS}

Lectins, sampling and specimens processing: This study was conducted in the period from February 2007 to July 2008. The characteristics of lectins used are shown in (Table 1). Twelve different species of rodents that belong to different families were selected.
Table 1: Characteristics of the utilized lectins

\begin{tabular}{lll}
\hline Acronym & Lectin latin name & Preferential sugar specificity \\
\hline WGA & Triticum vulgaris & (GlcNAc b1, 4)n $\mathrm{n}^{\mathrm{a}}$ \\
PNA & Arachis hypogaea & Galb1, 3GalNAc ${ }^{\mathrm{b}}$ \\
\hline${ }^{\mathrm{a}}$ : GlcNAc, N-acetylglucosamine; ${ }^{\mathrm{b}}$ : GalNAc, N-acetylgalactosamine
\end{tabular}

The involved rodents were belonging to many families including the family of Muridae; consisting of Gerbilinae subfamily (Jerbillus nanus, Meriones Persicus, Meriones lybicus) Microtinae (Microtus transcaspicus, Ellobius fascocapillus, Microtus sp.) Dipodidae (Alactage elater, Jucullus blanfordi) and scuridae (Funambulus penantii, spermophillus folvus). The digestive tract of all involved rodents was removed properly and weight was measured and then proximal colon was cut into $2-3 \mathrm{~cm}$ segments, fixed by Bouin solution and 4 um thick paraffin-embedded sections were made and sections were stored at $4{ }^{\circ} \mathrm{C}$ for later use. Lectin histochemistry assay was conducted within 3 days of the paraffin-embedded sections storage in order to minimize any conformational changes might occur in mucin sugras.

Lectin histochemistry assay: Lectin binding was performed as previously reported by ${ }^{[12,13]}$. Two HorseReddish Peroxidase (HRP)-conjugated lectins were used (Sigma, USA), namely Arachias hypogaea, peanut (PNA) and Triticum vulgaris, Wheat Germ Agglutinin (WGA). Two hundreds ug of lectins were diluted in 800 uL of 0.1 M Phosphate-Buffered Saline (PBS). Two sections of colon were chosen and then hydrated and rinsed for $10 \mathrm{~min}$ in $0.1 \mathrm{M}$ PBS (pH7.4). Briefly, rehydrated sections were exposed to $3 \%$ hydrogen peroxide for $10 \mathrm{~min}$ to inhibit endogenous peroxidase activity and then incubated for $30 \mathrm{~min}$ at room temperature with peroxidase labeled lectin in $0.1 \mathrm{M}$ PBS. The activity of the HRP was then visualized histochemically by adding 2-3 drops of $0.005 \%$ 3-30diaminobenzidine (DAB) (Sigma, USA) mixed with $0.01 \%$ hydrogen peroxide in $0.05 \mathrm{M}$ Tris- $\mathrm{HCl}$ buffer at $\mathrm{pH} 7.5$ for $10 \mathrm{~min}$. All sections were counterstained with $1 \%$ solution of Alcian Blue at $\mathrm{pH} 2.5$ for five min. Finally, the sections were dehydrated through graded ethanol series, cleared in xylene and mounted in DPX (Fluka, Germany).

Staining analysis: The histochemical labeling of lectins employed was assessed double-blindly by two independent observers. The intensity of the labeling was classified and shown in (Table 2). Positive and negative control sections of rat colon were tested in parallel. The negative control sections were done by adding $0.1 \mathrm{M}$ PBS devoid of any lectins. The control positive sections were these sections that gave consistently highly positive results for the used lectins. 
Table 2: The scoring system used for assessing the staining intensity of lectin binding assay ${ }^{[14]}$

\begin{tabular}{ll}
\hline Description & Grades \\
\hline Negative reaction & - \\
Weak & + \\
Moderate & ++ \\
Severe & +++ \\
Very severe & ++++ \\
\hline
\end{tabular}

Statistical analysis: Data analysis was done by using SPSS version 12. Kruscal Wallis test was used to analyze the qualitative differences in the staining results of lectin binding assay. P-value less than 0.05 was considered as significant.

\section{RESULTS}

No reaction of PNA was observed in Longitudinal Muscle Layer, Circular Muscle Layer, Goblet cells in Channel and Goblet cells in surface of most studied rodents. Weak to moderate reaction of PNA was observed in other layers of colon. Severe reaction was observed in serosa layer of all studied rodents except dipodidae family Alactaga elater and Jaculus blanfordi. Weak to strong reaction of WGA was observed in different layers of colon of rodents except in Goblet cells in Channel, basement and Surface epithelium compartments of most rodent species. Reaction of glycoconjucates in colon sections of different rodents was summarized in (Table 3) and examples of lectin histochemistry was shown in Fig. 1-4. Eleven qualitative regional profiles $\left(\mathrm{x}_{1}-\mathrm{x}_{11}\right)$ were investigated and analyzed which are composed of the WGA and PNA lectins histochemistry reactions with glycoconjucates in 11 parts of the paraffin-embedded sections of colon of 12 rodent species. Remarkable difference was observed in the overall profiles of PNA lectin histochemistry in colon tissue sections particularly in the regional profile of $\mathrm{x}_{2}, \mathrm{x}_{5}, \mathrm{x}_{8} \mathrm{X}_{10}$ (Table 3). The overall profile among the 12 rodents species in WGA staining was different too. The most prominently variable regional profiles were $\mathrm{x}_{5}, \mathrm{x}_{8}, \mathrm{x}_{9}$ and $\mathrm{x}_{10}$. Therefore, the lectin histochemistry proved successful in the qualitative characterization of different species of rodents even though some species came from the same family. The use of Kruskal wallis test confirmed that all species of rodents were significantly different $(\mathrm{p}<0.05)$. In addition, these findings (Table 3 ) showed that lectins binding in $\mathrm{x}_{5}$ : mucosal layer, $\mathrm{x}_{8}$ : Absorptive cells in basement layer and $\mathrm{x}_{10}$ : Absorptive cells in surface were of utmost variability among the studied rodent species in both PNA and WGA lectins.

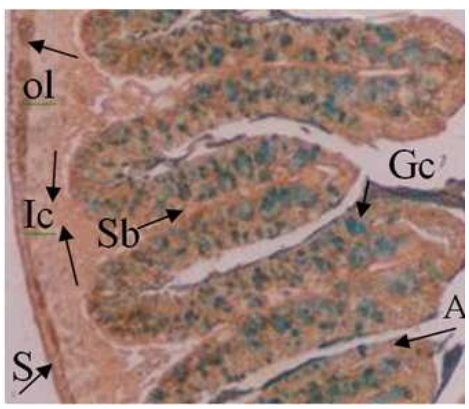

Fig. 1: Transverse section of proximal colon in Ellobius fascocapillus incubated with WGA at magnification 100X. $\mathrm{S}=$ Serosa layer with very severe reaction, $\mathrm{Ol}=$ Outer longitudinal muscle layer with severe reaction, Ic = Inner circular muscle layer with weak reaction, $\mathrm{Sb}=$ submucosal layer with moderate reaction, $\mathrm{Gc}=$ Goblet cells with no reaction, $\mathrm{A}=$ Absorbtive cells with moderate reaction

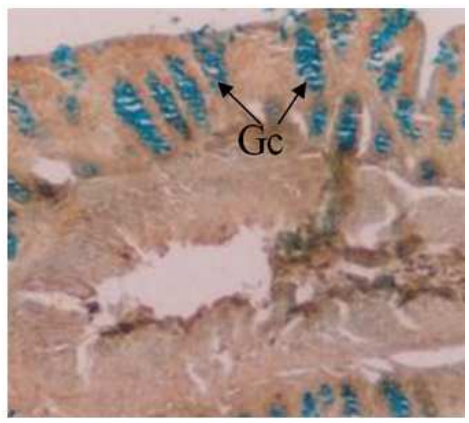

Fig. 2: Transverse sections of proximal colon in Funumbulus pennantii (F.p) in reaction with PNA lectin at magnification 100X. Gc $=$ Goblet cells showed no lectin reaction

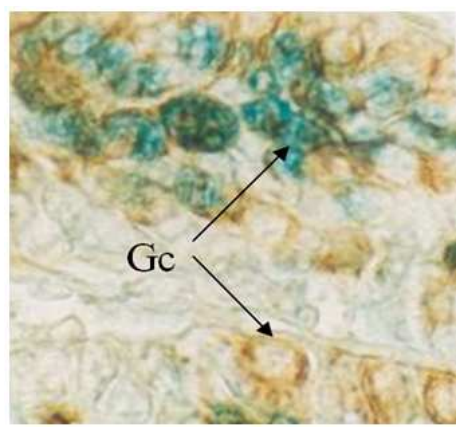

Fig. 3: Transverse sections of proximal colon in Meriones lybicus (M.l) in reaction with WGA lectin at magnification $100 \mathrm{X} . \mathrm{Gc}=$ Goblet cells, severe reaction was observed 
Am. J. Biochem. \& Biotech., 5 (1): 7-13, 2009

Table 3: The Binding of PNA and WGA lectins in colons of 12 species of rodents are in terms of 11 qualitative regional profiles ( $\left.\mathrm{x}_{1}-\mathrm{x}_{11}\right)$ that in turn constitute the overall profile

\begin{tabular}{|c|c|c|c|c|c|c|c|c|c|c|c|}
\hline $\begin{array}{l}\text { Name of } \\
\text { species }\end{array}$ & $\begin{array}{l}\text { Serosa } \\
\text { layer } \\
\mathrm{X} 1\end{array}$ & $\begin{array}{l}\text { Longitudinal } \\
\text { muscle layer } \\
\text { X2 }\end{array}$ & $\begin{array}{l}\text { Circular Muscle } \\
\text { layer } \\
\text { X3 }\end{array}$ & $\begin{array}{l}\text { Sub mucosal } \\
\text { layer } \\
\text { X4 }\end{array}$ & $\begin{array}{l}\text { Mucosa } \\
\text { Layer } \\
\text { X5 }\end{array}$ & $\begin{array}{l}\text { Goblet cells } \\
\text { in basement } \\
\text { X6 }\end{array}$ & $\begin{array}{l}\text { Goblet cells } \\
\text { in channel } \\
\text { X7 }\end{array}$ & $\begin{array}{l}\text { Absorptive } \\
\text { cells in } \\
\text { basement } \\
\text { X8 }\end{array}$ & $\begin{array}{l}\text { Absorptive } \\
\text { cells in } \\
\text { channel } \\
\text { X9 }\end{array}$ & $\begin{array}{l}\text { Absorptive } \\
\text { cells in } \\
\text { surface } \\
\text { X10 }\end{array}$ & $\begin{array}{l}\text { Epithelium } \\
\text { surface } \\
\text { luminal } \\
\text { X11 }\end{array}$ \\
\hline$M . m$ (PNA) & ++++ & - & - & ++ & + & + & - & + & + & ++ & ++ \\
\hline$R . n$ (PNA) & ++++ & - & - & ++ & + & - & - & + & + & + & - \\
\hline$M . l$ (PNA) & ++++ & + & - & ++ & ++ & - & - & + & + & + & - \\
\hline$M . p$ (PNA) & ++++ & +++ & + & + & ++ & - & - & + & + & + & - \\
\hline$J . n$ (PNA) & ++++ & - & - & ++ & + & - & - & + & + & ++ & _ \\
\hline M.t (PNA) & +++ & - & - & + & + & + & ++ & ++ & + & + & + \\
\hline$M . i$ (PNA) & +++ & - & - & ++ & - & - & - & - & - & _- & - \\
\hline E.f (PNA) & ++++ & +++ & ++ & ++ & ++ & - & - & ++ & ++ & ++ & ++ \\
\hline A.e (PNA) & - & - & - & ++ & ++ & - & - & + & + & + & _- \\
\hline$J . b$ (PNA) & - & - & - & ++ & ++ & - & - & - & - & - & - \\
\hline$F \cdot p$ (PNA) & ++++ & - & - & ++ & - & - & - & - & - & _ & - \\
\hline$S . f$ (PNA) & ++++ & - & - & ++++ & - & - & - & + & + & _- & _- \\
\hline M. $m$ (WGA) & ++++ & +++ & ++ & ++ & ++ & + & ++++ & ++ & ++ & ++ & - \\
\hline R.n (WGA) & ++++ & +++ & ++ & ++ & ++ & +++ & +++ & ++ & ++ & + & - \\
\hline$M . l$ (WGA) & ++++ & +++ & ++ & ++ & ++ & ++++ & ++++ & ++ & ++ & + & - \\
\hline M.p (WGA) & ++++ & +++ & - & ++ & + & - & - & + & + & + & - \\
\hline$J . n$ (WGA) & ++++ & +++ & - & ++ & + & - & _- & + & + & ++ & - \\
\hline M.t (WGA) & ++++ & +++ & - & + & + & + & ++ & ++ & - & + & - \\
\hline$M . i$ (WGA) & ++++ & +++ & - & ++ & - & - & - & _- & ++ & _- & _- \\
\hline E.f (WGA) & ++++ & +++ & ++ & ++ & ++ & - & - & ++ & + & ++ & ++ \\
\hline A.e (WGA) & ++++ & +++ & ++ & ++ & ++ & - & - & + & - & + & - \\
\hline$J . b$ (WGA) & ++++ & +++ & ++ & ++ & ++ & - & - & _ & - & _ & _ \\
\hline$F . p(\mathrm{WGA})$ & ++++ & ++ & - & ++ & - & - & - & _- & + & _- & - \\
\hline$S . f$ (WGA) & ++++ & +++ & ++ & ++++ & - & - & - & + & + & - & _- \\
\hline
\end{tabular}

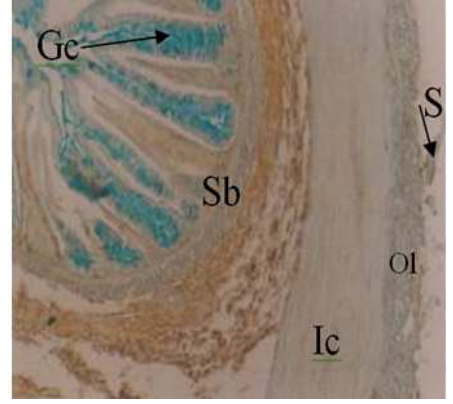

Fig. 4: Transverse sections of proximal colon in Alactage elater (A.e) with PNA lectin at magnification $100 \mathrm{X}$. $\mathrm{Sb}=$ submucosal layer, moderate reaction. $\mathrm{S}=$ Serosa layer, $\mathrm{Ol}=$ Outer longitudinal muscle layer and Ic $=$ Inner circular Muscle Layer, $\mathrm{Gc}=$ Goblet cells all showed no reaction with lectin

\section{DISCUSSION}

The digestive tract of rodents is important for phylogenic characterization due to its adaptation to different diets and its variability shown in different environments and taxonomic studies. In order to achieve a good analysis between biology and ecology in rodents and to utilize them biosystematically, there is a need to study rodents histochemically. Colon is an essential organ in the absorption of water and carbohydrates and encompasses a wide range of different cells actively associated with species, type of diet and the environment. Therefore, colon specimens of rodents were used in this study to monitor differences among different species of rodents. This study was conducted on the proximal colon of different species of rodents. This was essential to identify various sugar residues in the oligosaccharide sequences of mucin glycoconjugates produced by different mucous cells via using lectin histochemistry. The colon of rodents differs in the type and distribution of secreted mucus. Mucus is produced by a number of cell types and differs both in quantities of acidic and neutral glycoconjugates and in the lectin-binding pattern $^{[9]}$.

It is known that lectins can be valid markers for the diagnosis of various diseases, such as neoplastic alterations ${ }^{[5]}$. The variations in lectin binding patterns also allow estimating possible variations in the carbohydrate fraction of mucins depending on the cellular diversity or differentiation. Therefore, lectins can be useful for comparative studies on the variation of mucosal carbohydrate composition in the same organ types among animals of different species ${ }^{[15]}$.

PNA and WGA lectins showed weak reaction than WGA. Nevertheless in some parts, it showed high intensity which was mostly due to increasing 
compounds with terminal sugars and there were parts with no color which is a sign of absence of sugar in this layer $^{[16]}$.

In this study, mostly negative PNA reaction was found in most species studied in regard to longitudinal muscle layer, circular muscle layer, goblet cells in Channel and goblet cells in surface and in epithelial surface cells of all the studied rodents. Therefore, glycocojugates with terminal (Galb1,3GalNAc)n group are absent in this layers. Nevertheless, this terminal sugar was observed in high quantity in serous and submucosal layer of all rodent except dipodidae (Alactage elater and Jucullus blanfordi).

PNA lectin proved useful in discriminating the studied 12 species of rodents. The overall profile of PNA lectin histochemistry was qualitatively and quantitatively (staining intensity) unique for each species. The lectin staining in longitudinal muscular, mucosal and absorptive cells in base and surfaces showed the greatest variability among the studied species and the overall profile owes greatly its discrimination to these 4 parts of colon tissue.

The histochemical patterns of the various species studied also showed remarkable differences despite the similarity of their morphologic appearances. The terminal sugar recognized by WGA was (GlcNAc b1,4)n. This terminal sugar was observed in extreme high quantity in serous and submucosal layers of colon in all studied rodents and in longitudinal muscular layer except in Funambulus penantii. Very little (GlcNAc b1,4)n terminal sugar was monitored in goblet cells in most of species except in some species where staining ranged from weak to very severe reaction. Goblet cells of M.l, M.m and R.n species in Lieberkuhn's glands responded to WGA lectin with high intensity and some of them showed no reaction to this lectin which is due to the diversity of different types of mucus in goblet cells of these species. The epithelial surface cells also showed a dominant negative staining of WGA lectin. However, WGA lectin staining, like PNA, showed successful discriminating potential among the 12 studied species of rodents. The overall profile variability in WGA lectin histochemistry staining was greatly due to the highly variable staining in mucosal and absorptive cells in basement, channel and surface cells.

The findings of the current study revealed that the mucosal and absorptive layers in colon of the studied rodent species showed the best phylogenic discriminating potential upon using histochemistry of both PNA and WGA lectins. This provided evidence that cells of close contact with intestinal lumen have more variable pattern of sugars expression and subsequently the greatest variability in lectin staining. This gives a clue on the effect of the dietary pattern and environmental factors on these cells as well as shows that different species of rodents react in different way to these factors. The similarities and differences of sugars contents are individual variations, the nature of which may reflect dietary, genetic, or other unknown influences ${ }^{[17]}$.

The variations of the lectin binding pattern allow to estimate possible variations in the carbohydrate fraction of mucins depending on the cellular diversity or differentiation. A study reported recently the development of colonic epithelial cell hyperproliferation in rodents following ingestion of western style diets ${ }^{[18]}$ These lectin histochemical observations make available a uniform comparative basis for the normal distribution of mammalian gastrointestinal glycocojugates which should facilitate their study in diverse pathological conditions.

The findings of this study and previous reports reveal originate from differences in the living environments. Thus, histochemical studies of mucopolysacharrids or enzymes of colon of animals with diversified nutritional habits may refer to what the animal eats and consequently what the colon secretes. For instance, a colon of a specimen with a protein-rich diet has higher levels of protease enzymes comparing with a specimen with lower levels of protein. This fact applies to specimens with different environments and nutritional habits.

The findings of the current study indicated the presence of significant distinctions in the carbohydrates and glycoproteines in the different layers of colon tissues of the studied rodents. The different carbohydrate structures in mucosa and the different layers of colon tissues of the studied rodents may represent a mechanism for modulation of the composition of the protective mucosal and absorptive layers correlated to the specific functions of intestine. Few similar researches were published. Therefore, more comparative studies are needed to shed some light on the functions and phylogenic evaluation of animals using lectin histochemistry ${ }^{[19]}$. In addition to phylogenic characterization, the use of lectins to target the diseased tissues of colon is an interesting development but much work remains to be done. Lectins also have potential in mucosal vaccines. Moreover, advanced drug delivery systems using lectins can be realized and rigorous evaluation of their toxicity and immunogenicity will be required. Lectins clearly offer a number of possibilities for efficient GI drug targeting systems in the future ${ }^{[20]}$. 


\section{CONCLUSION}

Taken together, lectins can be usefully exploited in the comparative studies on the variation of mucosal carbohydrate composition in the same organ types among animals of different species. The most abundant layers in colon for glycoconjugates and lectin staining are mucosal and absorptive cells. This provided an opportunity to get use of these cells in the phylogenic characterization due to their close contact to intestinal lumen and environmental factors that are highly variable among many different species. The use of lectin histochemistry proved to be valid method for phylogenic characterization of rodents, may be for other animals, depending on colon tissues. Moreover, Colon tissues proved to be highly distinct and variable among species of animals. Therefore, this assay can also be used in determining the diet nature, geographical variation, diseases affection on different species of animals.

\section{REFERENCES}

1. Peetermans, W.E., N. Van De Vyver, Y. Van Laethem, P. Van Damme, N. Thiry, P. Trefois, P. Geerts, M. Schetgen, R. Peleman, B. Swennen and J. Verhaegen, 2005. Recommendations for the use of the 23valent polysaccharide pneumococcal vaccine in adults: A Belgian consensus report. Acta Clin. Belg., 60: 329-337.

https://portal.health.fgov.be/pls/portal/url/ITEM/2B 057882C9811279E04400144F3EAABC

2. Adam, E., 1992. A dot blot technique for the analysis of interaction of lectin with glycsominoglycan. HistoChem. J., 24: 453-455. DOI: $1846385 / 13 \mathrm{xx}$

3. Vasta, G.R., H. Ahmad, N.E. Fink and M.T. Elola, 1994. Animal lectins as self/ non self recognition molecules. Ann. N.Y. Acad. Sci., 15: 55-73. http://www.annalsnyas.org/cgi/content/abstract/712 $/ 1 / 55$

4. Szentkuti, L. and M.L. Enss, 1998. Comparative Lectin-histochemistry on the pre-epithelial mucus layer in the distal colon of conventional and germfree rats. Comparat. Biochem. Physiol. Part A: Mol. Integ. Physiol., 119: 379-386. DOI: S1095643397004340 [pii]

5. Brooks, S.A. and D. Wilkinson, 2003. Validation of a simple avidin-biotin detection method for Helix Pomatia Lectin (HPA) binding as a prognostic marker in cancer. Acta Histochem., 105: 205-212. DOI: 10.1078/0065-1281-00705
6. Faraidi, C.C. and S. Falugic, 1996. Glyconjugate expression change during rana dalmatina early development. Eur. J. HistoChem., 40: 67-74. http://www.ejh.it/Article.php?-recid=3763

7. Griffith, C.M. and M.J. Wiley, 1990. Distribution of cell surface glycoconjugates during secondary neurulation in the chick embryo. Anat. Rec., 226: 81-90. DOI: 10.1002/ar.1092260110

8. Wu, A.M., 2003. Carbohydrate structural units in glycoproteins and polysaccharides as important legends for Gal and GalNAc reactive lectins. J. Biomed. Sci., 10: 676-688. DOI: 10.1159/000073954

9. Scillitani, G., S. Zizza, G.E. Liquori and D. Ferri, 2007. Lectin histochemistry of gastrointestinal glycoconjugates in the greater horseshoe bat, Rhinolophus ferrumequinum. Acta Histochem., 109: 347-357. DOI: S0065-1281(07)00043-8 [pii]

10. Domeneghini, C., S. Arrighi, G. Radaelli, G. Bosi and A. Veggetti, 2005. Histochemical analysis of glycoconjugate secretion in the alimentary canal of Anguilla anguilla L. Acta Histochem., 106: 477-487. DOI: S0065-1281(04)00090-X [pii]

11. Rouk, C.S. and B.P. Glass, 1970. Comparative gastric histology of five North and Central American bats. J. Mammal., 51: 455-490. http://www.ncbi.nlm.nih.gov/entrez/query.fcgi?cmd=Ret rieve $\& \mathrm{db}=$ PubMed\&dopt $=$ Citation\&list_uids $=5530005$

12. Ferri, D. and G.E. Liquori, 1992. Characterization of secretory cell glycoconjugates in the alimentary tract of the ruin lizard (Podarcis sicula campestris De Betta) by means of lectin histochemistry. Acta Histochem., 93: 341-349. http://www.ncbi.nlm.nih.gov/entrez/query.fcgi?cmd=Ret rieve $\& \mathrm{db}=$ PubMed $\&$ dopt $=$ Citation\&list_uids $=1382353$

13. Ferri, D., G.E. Liquori, L. Natale, G. Santarelli and G. Scillitani, 2001. Mucin histochemistry of the digestive tract of the red legged frog Rana aurora aurora. Acta Histochem., 103: 225-237. DOI: S0065-1281(04)70070-7 [pii]

14. Gong, H., W. Ye, T.F. Freddo and M.R. Hernandez, 1997. Hyaluronic acid in the normal and glaucomatous optic nerve. Exp. Eye Res., 64: 587-595. DOI: S0014483596902456 [pii]

15. Liquori, G.E., M. Mastrodonato, S. Zizza and D. Ferri, 2007. Glycoconjugate histochemistry of the digestive tract of Triturus carnifex (Amphibia, Caudata). J. Mol. Histol., 38: 191-199. DOI: 10.1007/s10735-007-9087-4

16. Damjanov, I., 1987. Lectin cytochemistry and histochemistry. Lab. Invest., 57: 5-20. http://www.ncbi.nlm.nih.gov/entrez/query.fcgi?cm $\mathrm{d}=$ Retrieve $\& \mathrm{db}=$ PubMed\&dopt=Citation\&list_uids =3298849 
17. Sheahan, D.G. and H.R. Jervis, 1976. Comparative histochemistry of gastrointestinal mucosubstances. Am. J. Anat., 146: 103-31. DOI: 10.1002/aja.1001460202

18. Yang, K., K. Fan, H. Newmark, D. Leung, M. Lipkin, V.E. Steele and G.J. Kelloff, 1996. Cytokeratin, lectin and acidic mucin modulation in differentiating colonic epithelial cells of mice after feeding Western-style diets. Cancer Res., 56: 4644-4648. http://www.ncbi.nlm.nih.gov/entrez/query.fcgi?cm $\mathrm{d}=$ Retrieve $\& \mathrm{db}=$ PubMed $\& \mathrm{dopt}=$ Citation\&list_uids $=8840978$
19. Danguy, A., R. Kiss and J.L. Pasteels, 1988. Lectins in histochemistry. A survey. Biol. Struct. Morphol., 1: 93-106.

http://www.ncbi.nlm.nih.gov/entrez/query.fcgi?cm $\mathrm{d}=$ Retrieve $\& \mathrm{db}=$ PubMed\&dopt=Citation\&list_uids $=3058217$

20. Woodley, J.F., 2000. Lectins for gastrointestinal targeting-15 years on. J. Drug Target., 7: 325-533. http://www.ncbi.nlm.nih.gov/entrez/query.fcgi?cm $\mathrm{d}=$ Retrieve $\& \mathrm{db}=$ PubMed\&dopt=Citation\&list_uids $=10721794$ 